\title{
BIOSYNTHESIS OF SINEFUNGIN BY CELL-FREE EXTRACT OF STREPTOMYCES INCARNATUS NRRL 8089
}

\author{
Halina Malina, Christiane Tempete and Malka Robert-Gero* \\ Institut de Chimie des Substances Naturelles, C.N.R.S., \\ 91190 Gif-sur-Yvette, France
}

(Received for publication April 14, 1986)

\begin{abstract}
The formation of sinefungin an antifungal and anti-parasitic nucleoside antibiotic was demonstrated in cell-free extracts from Streptomyces incarnatus. Incorporation studies as well as HPLC analysis showed that the immediate biosynthetic precursors of the antibiotic are $\mathrm{L}$-arginine and ATP. The biosynthesis was optimal when the cell-free extract was prepared from 72 hours mycelium and incubated at least 80 minutes with arginine and ATP. The presence of dithiothreitol, pyridoxal phosphate and $\mathrm{Mg}^{2+}$ in the incubation mixture was also necessary. When a membrane fraction was incubated under the same conditions with ATP and L-arginine, sinefungin production was not observed. A working hypothesis is put forward to explain the biosynthesis of this antibiotic.
\end{abstract}

The nucleoside antibiotic $32232 \mathrm{RP}$ or sinefungin was isolated at Rhône-Poulenc Laboratories from cultures of Streptomyces incarnatus NRRL $8089^{1)}$ and at Eli Lilly Research Laboratories from the fermentation broth of Streptomyces griseolus ${ }^{2}$. The antibiotic has a strong inhibitory effect on various fungi ${ }^{3)}$ and parasites ${ }^{4 \sim 7)}$, but is considered as nephrotoxic in vivo. Thus, we undertook a study with the aim to prepare new antibiotics by directed biosynthesis from modified biosynthetic precursors. The first step towards this goal was the definition of the biosynthetic pathway of sinefungin composed of a molecule of ornithine linked to the $5^{\prime}$ end of a molecule of adenosine via a carboncarbon bond. A cell-free extract prepared from a high producing variant of $S$. incarnatus ${ }^{8)}$ harvested in the production phase, was used in this study. The cell-free extracts were incubated with the various possible biosynthetic precursors of the antibiotic. Sinefungin was formed when the incubation mixture contained labeled arginine and ATP, in the presence of pyridoxal phosphate, dithiothreitol and $\mathrm{Mg}^{2+}$. No antibiotic was formed under the same conditions with ornithine. Based on these results a hypothesis is put forward to explain the biosynthesis of sinefungin.

\section{Materials and Methods}

Strain

$\bar{A}$ highly active variant P-12 obtained by regeneration of protoplasts of Streptomyces incarnatus NRRL 8089 was used ${ }^{8)}$. The antibiotic production was estimated by the agar diffusion disc plate method using Saccharomyces pastorianus as the test organism as described before ${ }^{8)}$.

\section{Mycelial Growth}

S. incarnatus $\mathbf{P}-12$ was grown in a medium which consisted of yeast extract $0.4 \%$, malt extract $1 \%$ and glucose $2 \%$. The mycelium was centrifuged after various times of culture in a Sorvall refrigerated centrifuge at $1,000 \times g$ for 10 minutes and washed three times with $0.05 \mathrm{M}$ phosphate buffer, pH 7, containing $0.1 \%$ of $\beta$-mercaptoethanol.

\section{Preparation of the Cell-free Extract}

The washed mycelium from $100 \mathrm{ml}$ of culture was resuspended in $10 \mathrm{ml}$ of the same buffer as 
above and was frozen in dry ice-methanol followed by disruption in a Hinton press at $360 \mathrm{~atm}$. During the disruption $10 \%$ glycerol was added to the buffer in order to avoid cell damage due to freezing.

The complete disruption of the mycelium was controlled under microscope. The cell-free extract was centrifuged at $100,000 \times g$ for 1 hour to separate the cytosol and the membrane fraction. The supernatant was dialyzed overnight against $0.05 \mathrm{~m}$ phosphate buffer, $\mathrm{pH} 7$.

Nucleic acid were precipitated by a final concentration of $2.5 \%$ streptomycin and eliminated by centrifugation at $5,000 \times g$ during 10 minutes. The proteins were then fractionated with ammonium sulfate. The active fraction precipitated at $40 \sim 70 \%$ saturation (fraction II).

The precipitate was centrifugated at $10,000 \times g, 15$ minutes and dissolved in a minimal volume of phosphate buffer and dialyzed overnight against the same buffer.

Incorporation studies: The incubation mixture contained in $100 \mu \mathrm{l}, 0.5 \mathrm{mg}$ of proteins from the fraction mentioned above and in final concentration of $4 \mathrm{~mm}$ unlabeled precursors, of $0.1 \mathrm{~mm}$ pyridoxal phosphate (PLP), of $0.1 \mathrm{~mm}$ magnesium chloride and $2 \mu \mathrm{Ci}$ of radioactive precursor. After 80 minutes of incubation at $37^{\circ} \mathrm{C} 2 \mu \mathrm{l}$ of the mixture was analyzed on silica gel thin-layer plates in two different solvent systems composed of chloroform-methanol-28\% $\mathrm{NH}_{4} \mathrm{OH}(1: 3: 1)$ and ethanol-33\% $\mathrm{NH}_{4} \mathrm{OH}(5: 4)$. Co-chromatography with authentic sinefungin sample was carried out. Autoradiography was performed using X-Omat AR Kodak film.

The radioactive spots were scrapped off and the radioactivity was measured in $5 \mathrm{ml}$ of aqueous counting scintillant (ACS) (Amersham).

The radioactive precursors used had the following specific activities; $\left[U_{-}{ }^{14} \mathrm{C}\right]$ adenosine $500 \mathrm{mCi}$ / mmol, $\left[U-{ }^{14} \mathrm{C}\right] \mathrm{ATP} 515 \mathrm{mCi} / \mathrm{mmol}, \mathrm{L}-\left[U-{ }^{14} \mathrm{C}\right]$ arginine monochlorhydrate $336 \mathrm{mCi} / \mathrm{mmol}$, and $\mathrm{L}-[$ guanido$\left.{ }^{14} \mathrm{C}\right]$ arginine monochlorhydrate $56 \mathrm{mCi} / \mathrm{mmol}, \mathrm{L}-\left[U_{-}{ }^{14} \mathrm{C}\right]$ ornithine monochlorhydrate $200 \mathrm{mCi} / \mathrm{mmol}$.

Identification of the Products Formed in the Incubation Mixture

The incubations were carried out as above but in a volume of $0.4 \mathrm{ml}$ and only unlabeled precursors were used. After incubation an equal volume of ethanol was added to the reaction mixture to inactivate and to precipitate the proteins. This was then centrifuged at $1,000 \times g$ for 15 minutes. The supernatant was evaporated to dryness under vacuum and re-dissolved in $0.4 \mathrm{ml}$ water. The analysis was performed using a Beckman HPLC apparatus with two pumps 1144, injector $421 \mathrm{~A}$, and variable wavelength detector $730 \mathrm{LC}$ (Kontron). The analytic column used was ODS Nucleosil $5 \mu \mathrm{m}$. The continuous gradient used to separate the compounds was composed of solvent A; $0.05 \mathrm{M} \mathrm{am}$ monium dihydrogen phosphate buffer, $\mathrm{pH} 6$, and solvent $\mathrm{B}$; methanol, with the following elution programme: B: $0 \% 5$ minutes, 0 to $10 \% 10$ minutes, $10 \% 5$ minutes, $10 \%$ to $0 \% 5$ minutes and $0 \%$ 5 minutes.

\section{Protein Concentration}

Protein concentration was determined using crystalline bovine serum albumin as standard by the LOWRY procedure? .

\section{Results}

As ornithine can be formed biosynthetically from arginine, and considering the possible similarity of sinefungin and $S$-adenosylmethionine biosynthesis ${ }^{10)}$, ATP was also included in the incubation mixtures.

The first experiments were carried out using the supernatant of a cell-free extract after centrifugation at $100,000 \times g$. Sinefungin formation was demonstrated by HPLC analysis. The authentic samples used for the identification of the peaks had the following retention times in minutes: ATP 4.2 4.4, ADP 5.1, AMP 10.5, adenosine 23.0 24, sinefungin 5.4. Sinefungin under these conditions was formed only when the incubation mixture contained ATP and arginine (Fig. 1a). The presence of sinefungin was confirmed by coinjection of an authentic sample, having 5.4 minutes retention time (Fig. 1b). Sinefungin formation was not observed when ornithine or adenosine was used (Fig. 1c 
1e).

The cell-free extract was then purified further. As shown in Table 1 the sinefungin synthesizing activity was localized in the protein fraction precipitating between 40 and $70 \%$ of $\left(\mathrm{NH}_{4}\right)_{2} \mathrm{SO}_{4}$ saturation. As the boiled extract showed no activity, sinefungin formation seems to be an enzymatic reaction.

Fig. 1. HPLC analysis at $254 \mathrm{~nm}$ of the various incubation mixtures containing the enzyme source and the potential biosynthetic precursors.

(a) L-Arginine + ATP, (b) L-arginine + ATP + authentic sinefungin, (c) L-ornithine + ATP, (d) Larginine +adenosine, (e) L-ornithine + adenosine. Retention times are given in minutes.
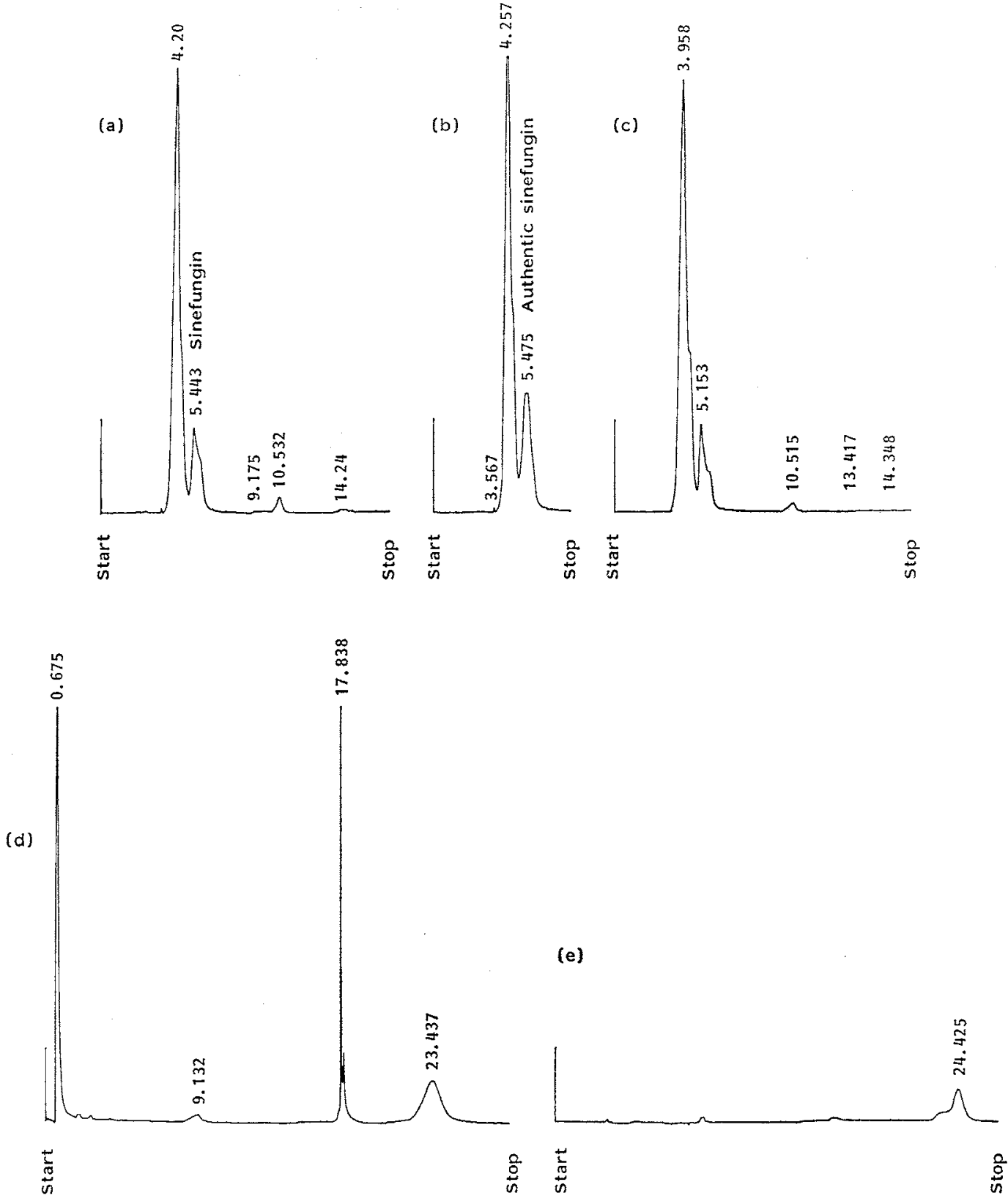
Table 1. Incorporation of $\left[U-^{14} \mathrm{C}\right]$ arginine into sinefungin in the presence of ATP and PLP as cofactor.

\begin{tabular}{cc}
\hline $\begin{array}{c}\text { Enzyme } \\
\text { preparations }\end{array}$ & $\begin{array}{c}\text { Incorporation into } \\
\text { sinefungin* } \\
\text { (nmol/mg protein) }\end{array}$ \\
\hline$\left(\mathrm{NH}_{4}\right)_{2} \mathrm{SO}_{4}$ concentration $(\%)$ & \\
$0 \sim 40$ & 0 \\
$40 \sim 70$ & 83.3 \\
$70 \sim 100$ & 1.5 \\
Boiled extract & 0 \\
\hline
\end{tabular}

* Background due to non-specific incorporation was deduced in each case.

The formation of sinefungin was observed only when labeled ATP or adenosine and uniformally labeled arginine were present in the reaction mixture. Guanido-group labeled arginine yielded unlabeled sinefungin (Fig. 2). Furthermore no sinefungin synthesis occured when the enzyme source was a membrane-rich fraction (Results not shown).

The influence of various cofactors on the biosynthesis of sinefungin was checked in the presence of different labeled precursors. As shown in Table 2 sinefungin formation was the most efficient with PLP.

Incorporation into sinefungin was observed when adenosine was incubated with arginine, but no sinefungin formation occured with ornithine as the labeled precursor.

As shown in Table 3 sinefungin biosynthesis could be enhanced by the presence of ions such as $\mathrm{Co}^{2+}, \mathrm{Mg}^{2+}$ and $\mathrm{Mn}^{2+}$.

Table 2. Influence of various cofactors on the incorporation of the radioactive precursors into sinefungin.

\begin{tabular}{lccccccccc}
\hline \multirow{2}{*}{ Cofactor } & \multicolumn{10}{c}{ Reaction mixture (nmol/mg protein) } \\
\cline { 2 - 9 } & $\begin{array}{c}\text { Arg* } \\
\text { ATP }\end{array}$ & $\begin{array}{c}\text { ATP* } \\
\text { Arg }\end{array}$ & $\begin{array}{c}\text { Orn* } \\
\text { ATP }\end{array}$ & $\begin{array}{c}\text { ATP* } \\
\text { Orn }\end{array}$ & $\begin{array}{c}\text { Arg* } \\
\text { ADE }\end{array}$ & $\begin{array}{c}\text { ADE* } \\
\text { Arg }\end{array}$ & $\begin{array}{c}\text { Orn* } \\
\text { ADE }\end{array}$ & $\begin{array}{c}\text { ADE* } \\
\text { Orn }\end{array}$ \\
\hline Control & 47.6 & 23.3 & 0.4 & 0.8 & 40.5 & 28.8 & 0.5 & 0.8 \\
PLP & 85.7 & 147.5 & - & 1.0 & 45.2 & 35.2 & 0.5 & 0.5 \\
NADP & 38.8 & 46.5 & 0.5 & 1.2 & 19.0 & 9.6 & 0.5 & 0.6 \\
NAD & 76.2 & 31.0 & 0.5 & 1.4 & 45.2 & 27.2 & 0.5 & 0.5 \\
NAD+Gly & - & 43.4 & - & - & 47.6 & 30.4 & - & - \\
NAD+PLP+Gly & 40.4 & - & - & - & 80.9 & 45.0 & - & - \\
\hline
\end{tabular}

The incubations were carried out with the enzyme preparation precipitated at $40 \sim 70 \%\left(\mathrm{NH}_{4}\right)_{2} \mathrm{SO}_{4}$ concentration.

* Labeled precursor. ADE: Adenosine.
Fig. 2. Autoradiogram of incubation mixtures containing the $100,000 \times g$ supernatant of Streptomyces incarnatus cell-free extract with the potential biosynthetic precursors of sinefungin.

1) $\mathrm{L}-\left[U-{ }^{14} \mathrm{C}\right]$ arginine $\left.+\mathrm{ATP}, 2\right) \mathrm{L}-\left[U{ }^{\mathrm{I}}{ }^{4} \mathrm{C}\right]$ arginine tadenosine, 3) L- $\left[U_{-}^{14} \mathrm{C}\right]$ ornithine $+\mathrm{ATP}$, 4) L$\left[U-{ }^{14} \mathrm{C}\right]$ ornithine + adenosine, 5) $\left[\right.$ guanido $\left.-{ }^{14} \mathrm{C}\right] \mathrm{ar}-$ ginine $+\mathrm{ATP}, 6$ ) $\left[\right.$ guanido $-{ }^{14} \mathrm{C}$ ]arginine + adenosine.

The chromatography was performed in the solvent at the following proportion; ethanol - $33 \%$ $\mathrm{NH}_{4} \mathrm{OH}(5: 4)$.

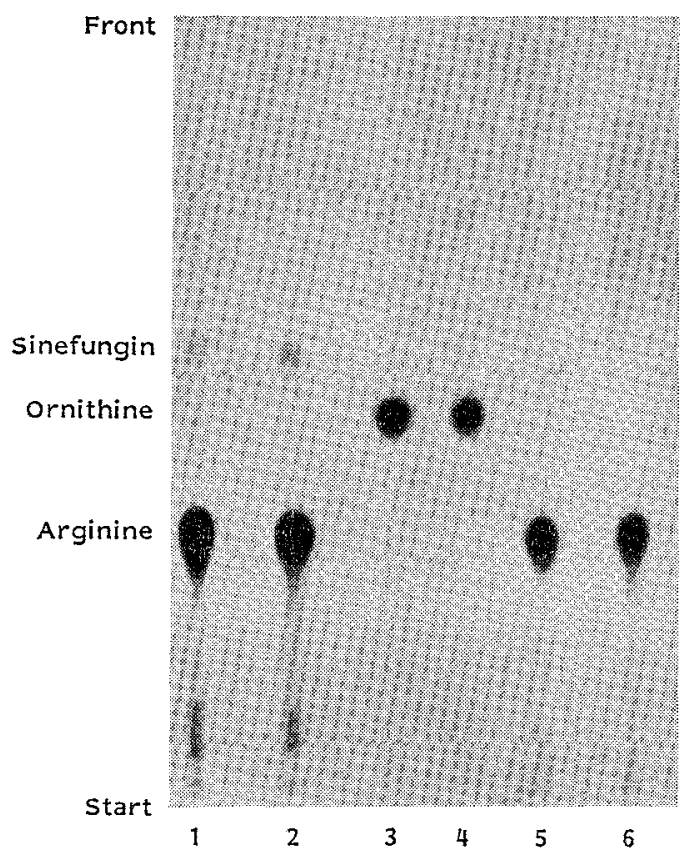


The influence of substrate concentration on sinefungin formation was studied using arginine and ATP in a concentration range of 2 to $10 \mathrm{~mm}$. The best results were achieved with $4 \mathrm{~mm}$ substrate concentration. HPLC analysis was used to study the formation of sinefungin with increasing protein concentrations. The incorporation of the labeled precursors increased as a function of protein concentration up to $6 \mathrm{mg} / \mathrm{ml}$ (Results not shown).

The effects of the age of the mycelium and the time of incubation of the cell-free extract on sinefungin formation were also determined. As shown in Fig. 3 the best activities were observed when the cell-free extract was prepared from a 72-hour culture. Sinefungin production reached the maximum after 80 minutes of incubation of the cell-free extract with the precursors (Results not shown).

\section{Discussion}

Previous work on sinefungin biosynthesis by $S$. griseolus was carried out by BERRY and ABBOTT using a complex medium. These authors postulated that, ornithine and adenosine are condensed in the terminal step of the biosynthesis ${ }^{11}$, however, evidence for such a reaction was never shown.

Two major reasons led us to re-investigate this hypothesis: First, the direct condensation between adenosine and ornithine is hardly conceivable; second, incorporation of precursors into sinefungin was measured by these authors 5 to 6 days after labeled compounds were added to the culture, which was not a chemically defined one. By this means early steps of the biosynthesis may have been overlooked and the radioactivity measured in sinefungin could have originated from a metabolically transformed precursor.

Fig. 3. Effect of the age of the mycelium on the sinefungin synthesizing activity.

The incubation mixture is composed of a dialyzed $100,000 \times g$ supernatant of the cell-free extract, arginine, ATP, and as usual, $\mathrm{Mg}^{2+}$, pyridoxal phosphate and dithiothreitol.

- Growth, $\mathbf{m}$ sinefungin synthesizing activity in vitro, $O$ production of sinefungin in vivo, $\wedge \mathrm{pH}$.

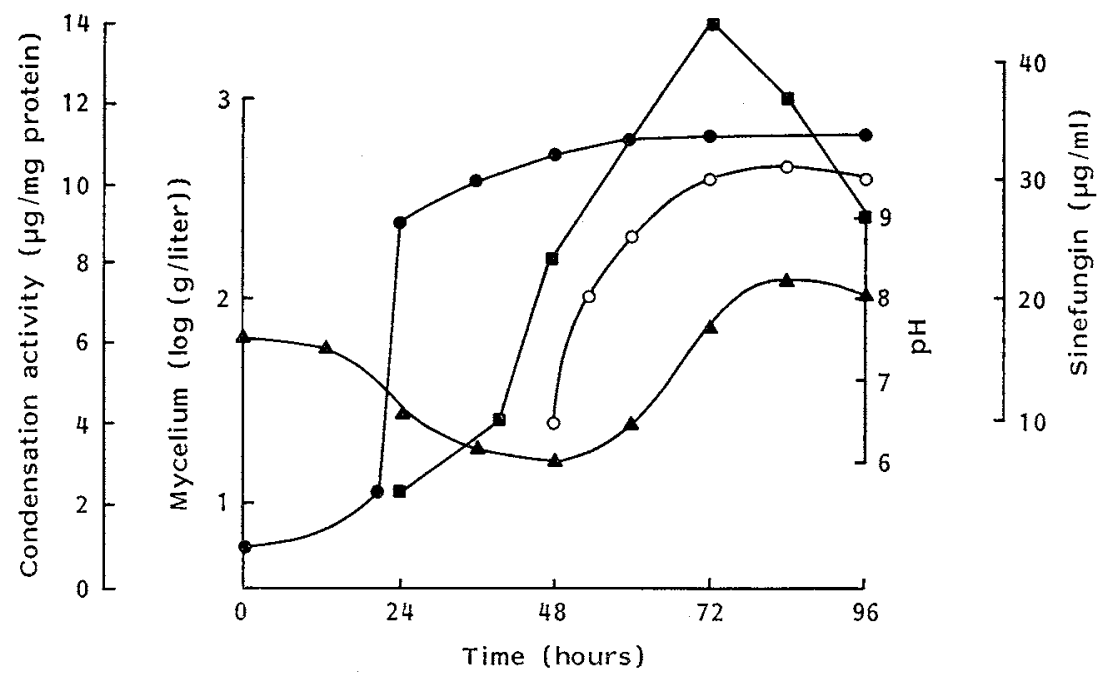


Fig. 4. Hypothetical pathway of sinefungin biosynthesis. A: Adenosine.
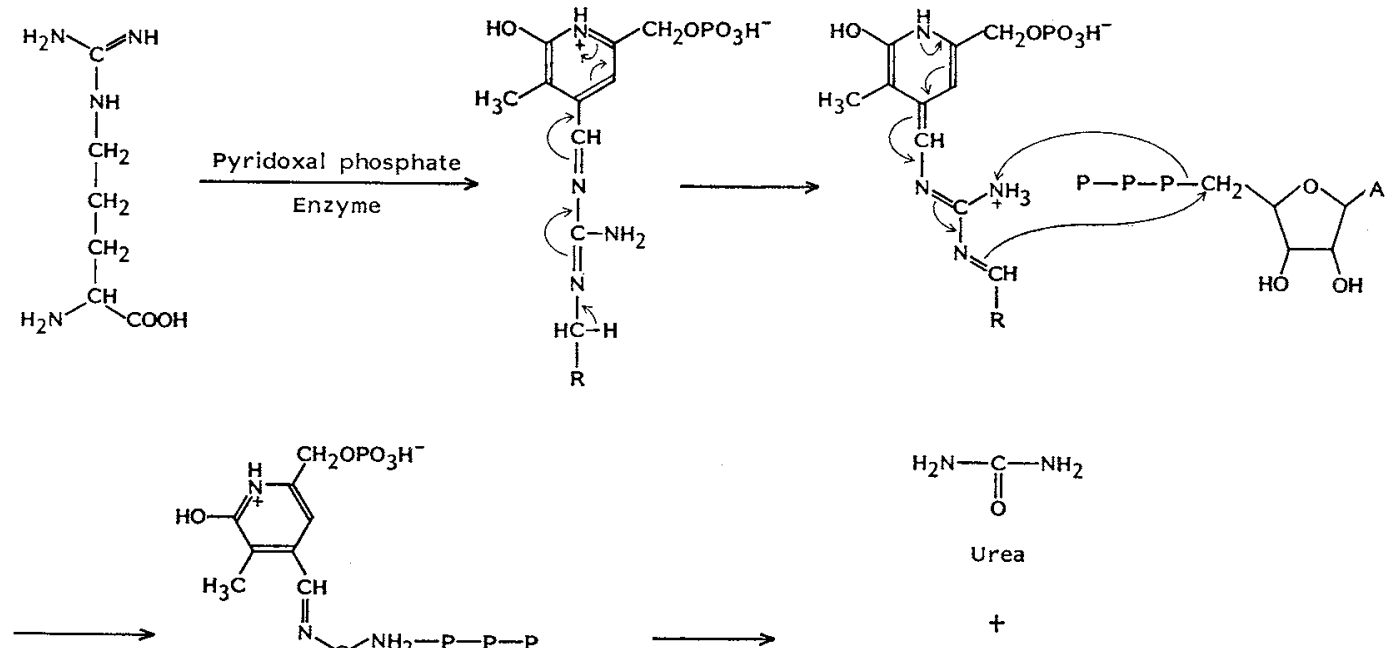<smiles></smiles>

$\mathrm{R}=\mathrm{CH}_{2} \mathrm{CH}_{2} \mathrm{CH}_{\mathrm{NH}_{2}}^{\mathrm{COOH}}$

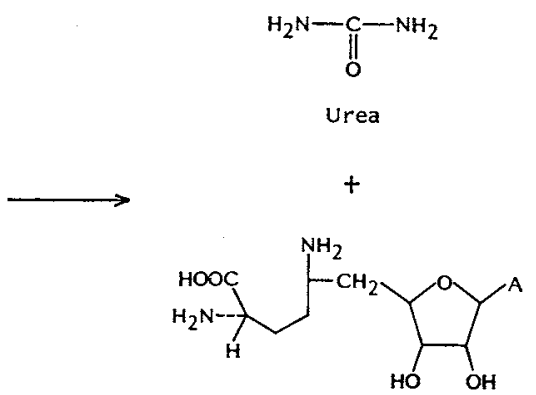

Sinefungin

Our previous studies with whole cells indicated that L-arginine and ATP rather than adenosine and ornithine are the immediate biosynthetic precursors of sinefungin ${ }^{122}$.

In this work we show that sinefungin can also be synthesized in vitro by a cell-free extract. Based on these results and on the fact that guanido-group labeled arginine yielded unlabeled sinefungin, we propose a working hypothesis to explain the biosynthesis of this antibiotic, which is shown in Fig. 4. According to our hypothesis the nitrogen atom of the guanido-group of arginine may be activated by an enzyme having pyridoxal phosphate as coenzyme and a Schiff base is formed. This activation produces a very reactive enamine which will react with the $5^{\prime}$ end of adenosine forming a $\mathrm{C}-\mathrm{C}$ bond. The elimination of the guanido-group would occur at the final step of the biosynthesis.

Further purification of the enzyme activity catalyzing the last step of the biosynthesis as well as the assays of preparation of sinefungin derivatives by incubation of arginine and ATP analogues with a cell-free extract are now in progress in our laboratory.

\section{Acknowledgments}

Dr. Halina Malina is recipient of a fellowship from World Health Organization.

This work was supported by grants from the World Health Organization UNDP/World Bank/WHO Special Programme for Research and Training in Tropical Diseases, from the Fondation pour la Recherche Médicale Française and la Ligue Nationale Française contre le Cancer.

\section{References}

1) Florent, Y.; Y. Lunel \& D. MANCY (Rhône-Poulenc Ind.): Nouvelle substance antifonginique, sa préparation et les compositions qui la contiennent. Fr. 7611141, Apr. 15, 1976

2) HAMLl, R. L. \& M. M. HoEHN: A9145, a new adenine-containing antifungal antibiotic. I. Discovery and isolation. J. Antibiotics 26: $463 \sim 465,1973$

3) GoRdee, R.S. \& T.F. Butler: A9145, a new adenine-containing antifungal antibiotic. II. Biological activity. J. Antibiotics $26: 466 \sim 470,1973$ 
4) Bachrach, U.; L. F. Schnur, J. El-On, C. L. Greenblatt, E. Pearlman, M. Robert-Gero \& E. Lederer: Inhibitory activity of sinefungin and SIBA (5'-deoxy-5'-S-isobutylthioadenosine) on the growth of promastigotes and amastigotes of different species of Leishmania. FEBS Lett. 121: 287 291, 1980

5) Trager, W.; M. Terschakovec, P. K. Chiang \& G. L. Cantoni: Plasmodium falciparum: Antimalarial activity in culture of sinefungin and other methylation inhibitors. Exp. Parasitol. 50: 83 89, 1980

6) Dube, D. K.; G. Mpimbaza, A. G. Allison, E. Lederer \& L. Rovis: Antitrypanosomal activity of sinefungin. Am. J. Chem. Trop. Med. Hyg. 32: 31 33, 1983

7) Ferrante, A.; I. Ljungstrom, G. Huldt \& E. Lederer: Amoebicidal activity of the antifungal antibiotic sinefungin against Entamoeba histolytica. Trans. R. Soc. Trop. Med. Hyg. 78: 837 838, 1984

8) Malina, H.; C. Tempete \& M. Robert-Gero: Enhanced sinefungin production by medium improvement, mutagenesis, and protoplast regeneration of Streptomyces incarnatus NRRL 8089. J. Antibiotics 38: $1204 \sim 1210,1985$

9) Lowry, O. H.; N. J. Rosebrough, A. L. FarR \& R. J. Randall: Protein measurement with the folin phenol reagent. J. Biol. Chem. 193: 265 275, 1951

10) Gross, A.; S. Geresh \& G. M. Whitesides: Enzymatic synthesis of $S$-Adenosyl-L-Methionine from LMethionine and ATP. Am. J. Biochem. and Biotechnol. 9: 415 422, 1983

11) BeRRY, D. R. \& B. J. АвBotT: Incorporation of ${ }^{14} \mathrm{C}$-labeled compounds into sinefungin (A9145), a nucleoside antifungal antibiotic. J. Antibiotics $31: 185 \sim 191,1978$

12) Malina, H.; C. Tempete \& M. Robert-Gero: Biosynthesis of sinefungin by S. incarnatus NRRL 8089. In Proceeding of the Sixth International Symposium on Actinomycetes Biology. Eds., G. SzABO \& M. GoOdFELlow, part A, pp. 259 261, Akademiai Kiado, Budapest, 1986 